\title{
Influence of water on the mechanical characteristics of rammed-earth material
}

\author{
Q.-B. Bui ${ }^{1,2}$, S. Hans ${ }^{1}$, J.-C. Morel $^{1} \&$ V. Mollion ${ }^{1}$ \\ ${ }^{I}$ Département Génie Civil et Bâtiment, Ecole Nationale des Travaux \\ Publics de l'Etat Lyon, France \\ ${ }^{2}$ LOQUIS Eco-construction, France
}

\begin{abstract}
Earthen materials in general and rammed-earth in particular are ancient materials used for construction since time immemorial. Some earthen structures built centuries ago are still performing satisfactorily. However, in a lot of cases, the problem of durability still raises questions, since earthen material is very sensitive to water and since the maintenance is not always well done. This paper presents a study on the influence of water on the mechanical characteristics (compressive strength, Young modulus and Poisson ratio) of rammed-earth material. Experiments on suction were also carried out to study the relationship between suction and mechanical characteristics of rammed-earth. The results show that for low water contents: which are from the dry state (in the atmospheric conditions) to $4 \mathrm{wt} . \%$, the mechanical properties are constant. Explanations of this result are presented in relation to the capillary force between particles at the microscopic level of the material.

Keywords: rammed-earth, influence of water, suction, compressive strength, young modulus, poisson ratio.
\end{abstract}

\section{Introduction}

The rammed earth is a clayey soil (earth) compacted into a formwork. The earth composition varies greatly but contains no organic component and enough clay, which acts as a binder between the grains, a mixture of silt, sand, gravel and stones with a diameter of a few centimeters. Compaction is performed using a water content considered optimum, i.e. that provides the highest dry density for a fixed compaction energy. The rammed earth is composed of several layers of 
earth. The earth is poured in layers about $15 \mathrm{~cm}$ thick into a formwork (wooden or metal), then it is rammed with a rammer (manual or pneumatic). After compaction, the thickness of each layer is $8-10 \mathrm{~cm}$. The procedure is repeated until completion of the wall. Detailed presentation of rammed earth material can be found in Walker et al. [1].

Rammed earth is an ancient material used for construction since immemorial times. Several rammed earth structures built centuries ago are still performing satisfactorily. A example is Horyuji Temple in Japan, a part of which was built with rammed earth approximately 1300 years ago and is still in good condition today (Hall and Djerbib [2]); or the case of a chateau in France which was built about 300 years ago by rammed earth and is still used today (Figure 1).

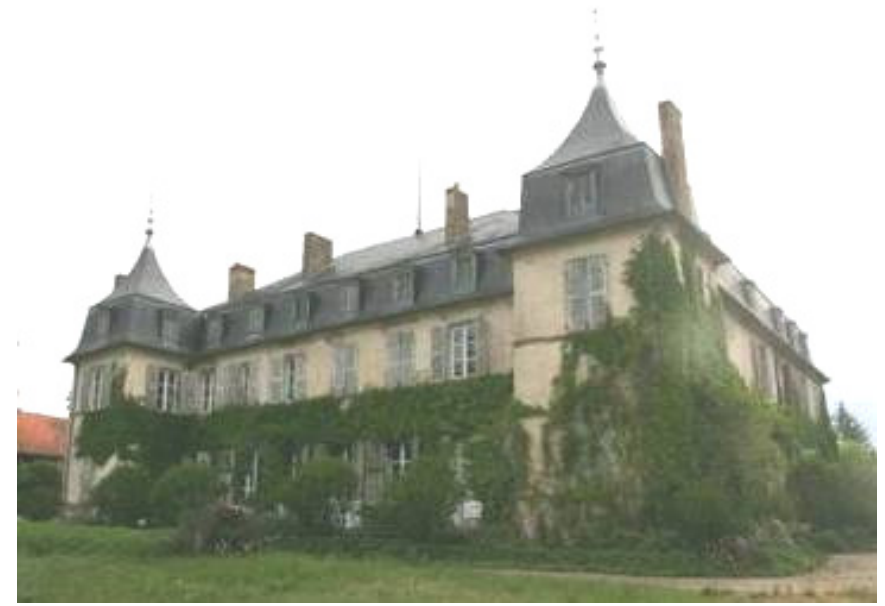

Figure 1: A chateau made of rammed-earth which was built about 300 years ago in France.

Nowadays, rammed earth construction is attracting renewed interest throughout the world thanks to its "green" characteristics in the context of sustainable development. That is why several researches have been carried out in recent years to study its characteristics: durability and sensitivity to water (Bui et al. [3], Hall and Djerbib [4]), thermal properties (Taylor et al. [5] and Taylor and Luther [6]), living comfort (Paul and Taylor [7]) and mechanical characteristics in compression (Bui et al. [8], [9], Maniatidis and Walker [10]).

For traditional rammed-earth materials, the only binder is clay, they are referred to as "rammed-earth" or "unstabilised rammed-earth". The strong point of this material is its very low embodied energy (Morel et al. [11]). Its weak point is the sensitivity to water. The presence of water can, on the one hand, cause erosion of the surface of the rammed-earth walls and on the other hand, increase the wall's water content which can decrease its strength. 
With industrialisation, modern rammed-earths appeared in which other binders were added, such as cement, hydraulic or calcium lime. They are called "stabilised rammed-earth", (SRE). The main advantage of stabilising the rammed-earth is to increase its durability and mechanical performance. The disadvantages of stabilisation are that it increases the construction cost and recycling becomes difficult.

Unstabilised rammed-earth is still the goal of scientific research for two main reasons. First, the heritage of rammed-earth buildings in Europe and the world is still important (Bui et al. [3], Fodde [12]). The maintenance of this heritage needs scientific knowledge on the material to have appropriate solutions. Then, applications of unstabilised rammed-earth in new construction are possible in several countries, particularly in the current context of sustainable development (Bui et al. [3]). The question "which conditions are suitable for the application of unstabilised rammed-earth?" awaits scientific answers, especially answers on the influence of water on rammed-earth walls.

Concerning the durability problem relative to the erosion of rammed-earth walls, in the previous study (Bui et al. [3]), the authors studied the erosion of rammed-earth walls exposed for 20 years in the natural climatic conditions in France. The study showed that in the studied climate, vis-à-vis the erosion problem, rammed-earth walls can exceed a hundred years without maintenance.

Concerning the influence of water content on characteristics of rammed-earth, Olivier and Mesbah [13] initiated the strategy which uses the suction theory to study the role of water in the compacted soil material. They showed that increasing the water content accompanied a decrease in the suction of compacted soil material. In a recent study, Jaquin et al. [14] studied the influence of suction on mechanical characteristics of rammed-earth material. This study found that suction was a source of strength in unstabilised rammed-earth, and that the strength increased as water content reduced. However, in that study, the authors only varied the water content between 5.5 and $10.2 \%$, while the water content of an unstabilised rammed-earth wall in normal conditions is around $2 \%$. That is why, in this paper, we study the influence of water on the mechanical characteristics of rammed-earth material, but with a greater variation of water content: from the wet state just after manufacturing (11\%) to dry state in atmospheric conditions (2\%). Samples in this study were manufactured and tested in unconfined compression at different water contents which correspond to different values of suction.

\section{Influence of water on the mechanical characteristics of rammed-earth material}

\subsection{Laboratory manufacturing process}

The soil used in this study contains $5 \%$ clay, $30 \%$ silt, $49 \%$ sand and $16 \%$ gravel. This is the same soil in the studies of Bui et al. [8] and[9], in which we analysed the parameters that can influence the sample representativeness (sample 
dimensions, compaction energy, manufacturing water content, density gradient in each layer of material). We showed that it was possible, from laboratory tests on homogeneous compressed earth blocks (CEBs) by simple homogenizing, to find the mechanical behavior of rammed-earth that is heterogeneous at the scale of $10 \mathrm{~cm}$. The disadvantage of this approach which uses CEBs is that we must know the dry densities of upper and lower parts in each layer of rammed-earth.

In the present study, to investigate the influence of water on the characteristics of rammed-earth material, we privileged reproducing the dynamic compaction and the layer superposition of rammed-earth material, without regard to the sample representativeness. That is why the approach mentioned above is not used; another approach is proposed which uses the automatic Proctor machine (Figure 2). The standard mold of the Proctor test was replaced by a mold of $16 \mathrm{~cm}$ diameter and $32 \mathrm{~cm}$ in height. To obtain the dry density of in-situ rammed-earth material $\left(1920 \mathrm{~kg} / \mathrm{m}^{3}[8]\right)$, a series of preliminary tests was conducted to determine the manufacturing water content and the soil amount to be poured into the mold for each layer, which are $11 \%$ for manufacturing water content and $2.2 \mathrm{~kg}$ for soil amount per layer. The received compaction energy of a point in the material corresponds to the Proctor energy $\left(e=0.6 \mathrm{~kJ} / \mathrm{dm}^{3}\right)$. For each sample, there are 6 superposed soil layers. The final height of the cylinder after the release is about $30 \mathrm{~cm}$.

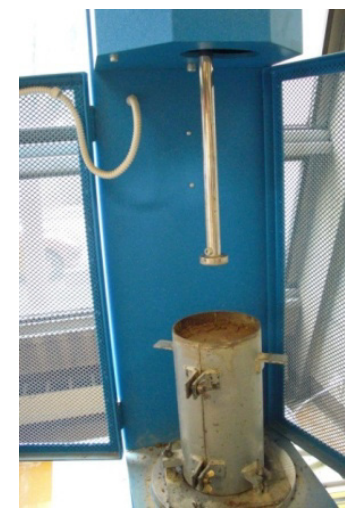

Figure 2: $\quad$ Automatic Protor machine and modified mould.

The soil was previously sieved through $2 \mathrm{~cm}$ screen to ensure a certain level of homogeneity in each soil layer of the samples which is about $5 \mathrm{~cm}$ thick.

The layer thickness of in-situ walls is about $10 \mathrm{~cm}$, which creates a density gradient in each layer: the upper part of each layer is more compacted and therefore denser than the bottom (Bui et al. [8]). The fact that the layer thickness of the samples which are produced in laboratory is about $5 \mathrm{~cm}$ causes the material to be more compact over the entire layer thickness, which corresponds more to the upper parts of the layers in the case of in-situ rammed-earth. So the disadvantage of this manufacturing strategy is that the sample is not representative for the in-situ material. To make a link between the results 
obtained on laboratory-fabricated cylindrical samples in this study with in-situ walls, a correlation coefficient is necessary. This correlation can be found by following a homogenisation process, presented in the previous study (Bui et al. [8]). Searching correlation coefficients is not the aim of this paper.

After compaction, the sample was removed from the mold. The bottom surface being in contact with the bottom of the mold during compaction was smooth and did not need resurfacing, while the upper surface was surfaced by a mortar (2chaux: 3 sable by weight) to obtain a smooth surface. During drying, the sample was left in laboratory atmosphere until the water content obtained a desired value for the test. This water content was verified by weighing the sample. Then, the sample was covered by plastic films for at least a week to keep the desired moisture content. Within this time, as the moisture could circulate within the sample, the sample was more homogeneous (avoiding the sample surface is drier than the sample heart). The sample was considered " $d r y$ " when there is no more loss of water content, although there is still residual moisture content in the sample (around 2\%). This "dry" state is the case of in-situ walls in normal conditions.

\subsection{Unconfined compression test}

\subsubsection{Test device}

In previous studies (Bui et al. [8] and [9]), the authors measured the longitudinal strain on the entire height of the sample. Since both top and bottom of the sample which are in contact with both top and bottom plates of the press, are not perfectly flat and are fretted, only the central part of the sample deforms homogeneously. Measuring longitudinal strain in the central part of the sample is thus more representative. In addition, to help determine the Poisson ratio, lateral strain measurements were also done. Figure 3(a) shows the configuration of a uniaxial compression test: extensometers measure the longitudinal strains and LVDT sensors measure lateral displacements which help to calculate the lateral strains.

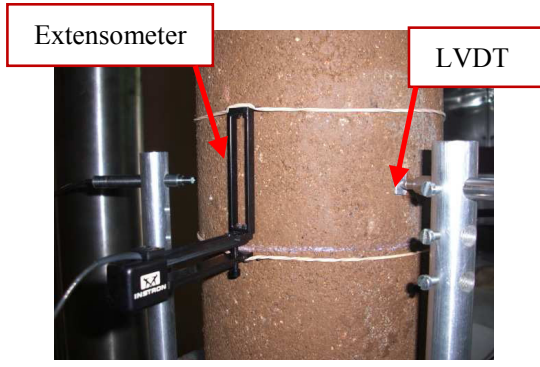

(a)

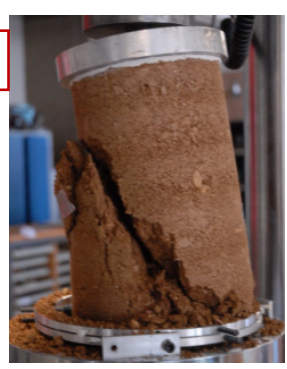

(b)

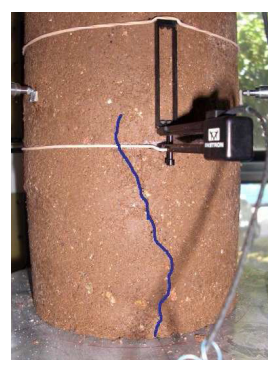

(c)

Figure 3: Measurement device on a sample (a); failure modes of force control (b) and displacement control (c). 
For each test, three extensometers and three LVDT sensors, arranged for an interval of $120^{\circ}$ on the radial plan, were used to verify the repeatability of results. An extensometer measures the strain between two points: one point at the center of a layer and the other point at the center of the upper layer. The distance between two points of extensometer is $6.2 \mathrm{~cm}$ while the thickness of a layer of the sample is about $5 \mathrm{~cm}$. The tests were controlled by displacement with a loading rate $0.1 \mathrm{~mm} / \mathrm{min}$.

Some tests were controlled by force $(3 \mathrm{kN} / \mathrm{min})$ to observe the difference between failure modes controlled by force and by displacement. For samples controlled by force, failure was inclined (Figure 3(b)) while for samples controlled by displacement, breaking cracks were vertical (Figure 3(c)). However, the failure forces did not differ between two control modes. Note that this difference in failure modes is already known in the case of concrete samples.

\subsubsection{Elasto-plastic behaviour of the material}

Several unloading-reloading cycles were done to observe the elasto-plastic behaviour of the material and observe the variation of the modulus following stress levels of the cycles (Figure 4).
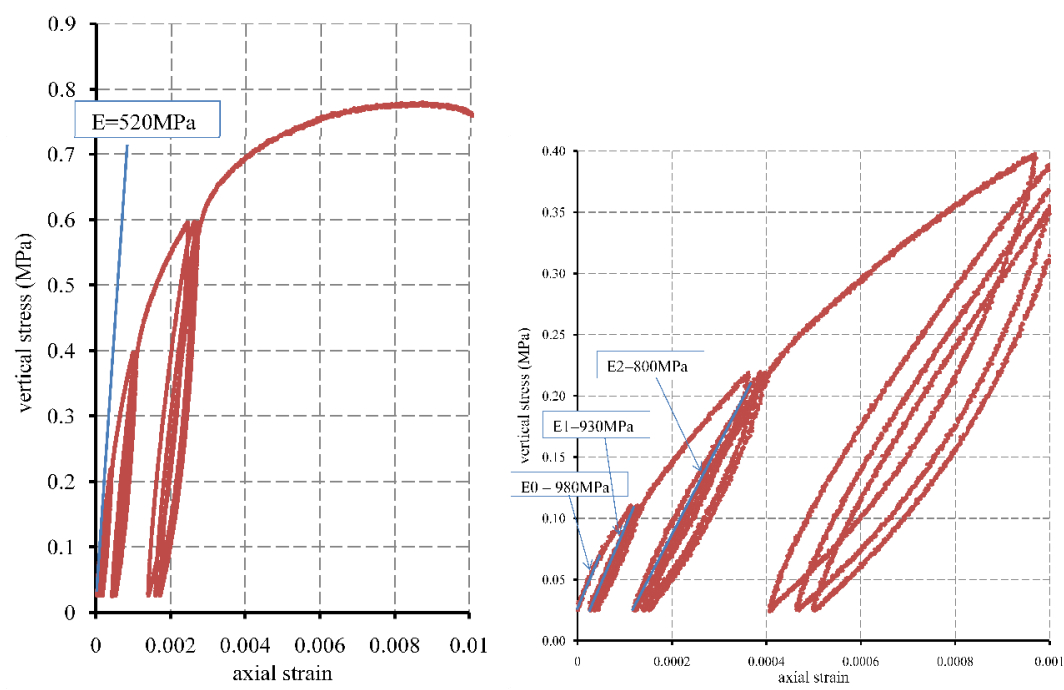

Figure 4: Elasto-plastic behaviour of the material (case of a sample at $9 \%$ in water content). On the right: a zoom of unloading-reloading cycles.

\subsubsection{Results of compressive strength, young modulus and poisson ratio}

Figure 5 shows variation of the compressive strength, the Young modulus (calculated from 0 to $0.2 \mathrm{MPa}$ ) and Poisson ratio of samples following water content. Concerning the modulus, only Young modulus is presented because it is often used in practice (for example Figure 4 on the left).

We see that the compressive strength is almost constant for samples almost dry $(w<4 \%)$. Then, it decreases rapidly following increasing water content of 


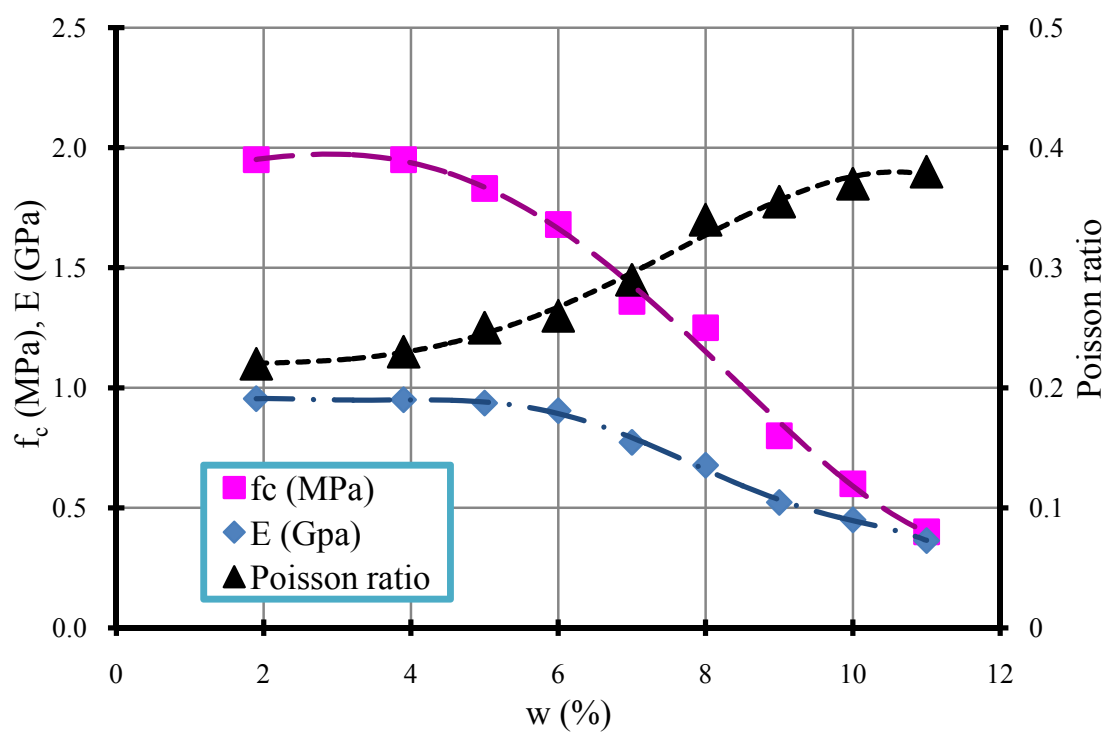

Figure 5: Variation of compressive strength, young modulus and poisson ratio following water content.

samples. A wet sample - just after manufacturing - has a strength which is about $20 \%$ the strength of a dry specimen.

For the Young modulus which were measured in the central part of the sample and from 0 to $0.2 \mathrm{MPa}$, there is only a slight variation for the case of samples having $w<6 \%$. A modulus about $1 \mathrm{GPa}$ is noted for the samples of these water contents. Then, a decrease of the modulus following the increase of the water content is observed.

Concerning the Poisson ratio, the latter is about 0.22 for dry samples $(w$ $<4 \%$ ), then, an increase of Poisson ratio following the water content and up to 0.38 for the wet samples, just after manufacturing. This variation is logical because when the material approaches the saturated state, the Poisson ratio approaches the value of 0.5 .

\section{Study on the suction}

In the study of Jaquin et al. [14], they showed that suction was the parameter that determined the mechanical characteristics of rammed-earth material. In our study, we will also study the suction in the rammed-earth, but with a larger range of water content.

Total suction $s$ is linked to the relative humidity $R H$ of the pore air through Kelvin's equation, which can be expressed as:

$$
s=u_{a}-u_{w}=-\frac{R \cdot T}{g \cdot w_{v}} \ln (R H)
$$


with: $u_{w}$ pore water pressure; $u_{a}$ pore air pressure; $R H$ relative humidity, which is the ratio of partial vapour pressure $P$ in the considered atmosphere and the saturation vapour pressure $P_{0}$ which depends on the temperature; $w_{v}$ is the molecular mass of water vapour; $g$ is the acceleration due to gravity $\left(g=9,81 \mathrm{~m} / \mathrm{s}^{2}\right) ; R$ is the universal gas constant; $T$ is the absolute temperature.

Evaporation of pore water is affected by the relative humidity of the pore air compared with that of the adjacent air outside the wall. In practice, drying of the wall will continue until the pore air humidity equals the humidity of the surrounding air.

There are several techniques to measure suction in unsaturated soils. A complete review of these techniques is presented in Delage and Cui [15]. We chose to use the technique of filter paper because it is simple and practical, usable in any laboratory having a weighing system accurate to $1 / 10,000 \mathrm{~g}$.

First, we placed on the surface of the sample having the desired water content, a triple of Whatman $n^{\circ} 42$ filter paper, which are frequently used and the calibration curves can be found in Delage and Cui [15]. Then, we covered the sample by plastic film to prevent evaporation. We left the sample for 7 days, so the moisture equilibrium was established between the sample and the filter paper. Then we extracted filter paper and determined the water content of the medium sheet, which was not polluted thanks to its non-contact with the sample surface. Using the calibration curve of the Whatman $n^{\circ} 42$ filter paper which is the relation of suction and the water content, we can determine suction of the paper and therefore the suction of the sample.

Figure 6 shows the variation of samples' suction following samples' water content. The variation of suction is slight for the case of dry samples $(w<4 \%)$. Then the suction rapidly decreases following the increase of water content.

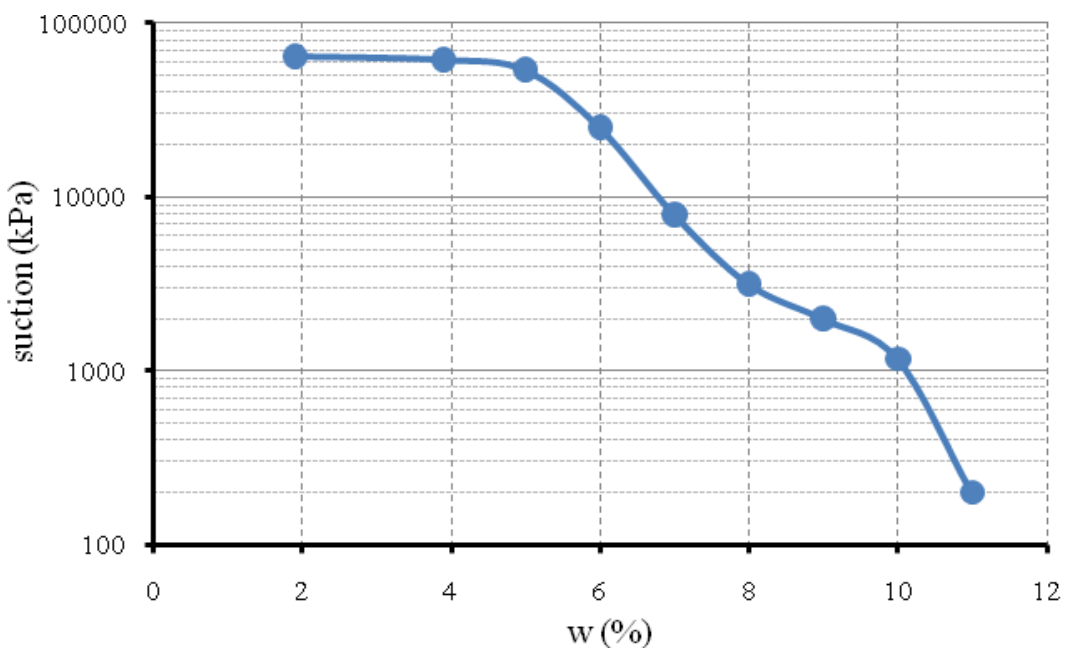

Figure 6: Variation of suction following water content. 


\section{Discussions}

\subsection{Constancy of the mechanical characteristics of dry samples $(w<4 \%)$}

According to the results presented in previous sections, we see that the mechanical characteristics (compressive strength, Young modulus, Poisson ratio) are dependent on the suction. Figure 7 illustrates the variation in compressive strength and tangent modulus following the suction.

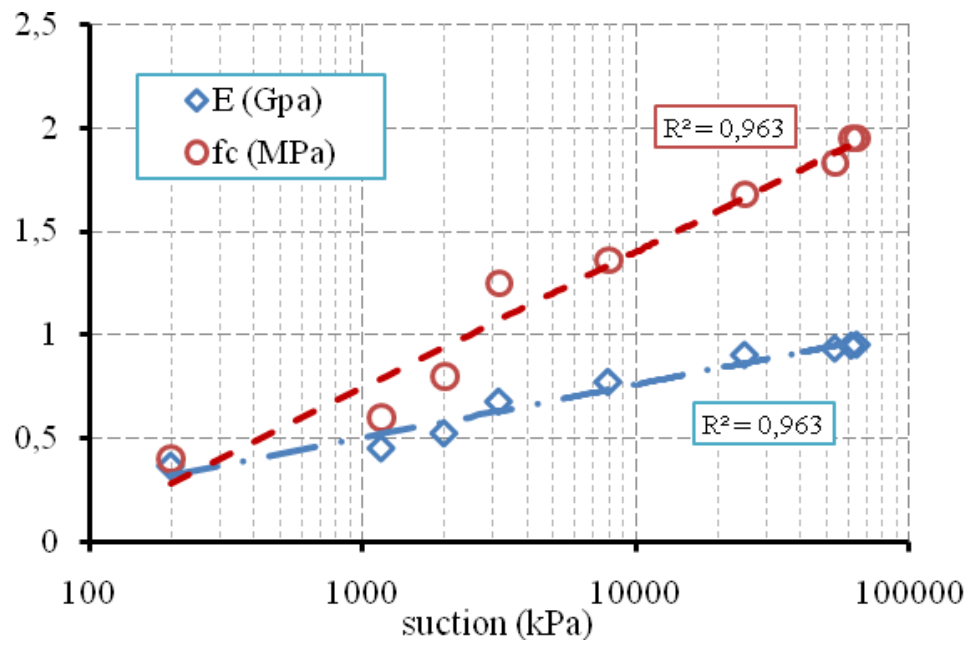

Figure 7: Variation of the suction as a function of the compressive strength $f_{c}$ and the elastic modulus $E$.

Here, the remark found by Jaquin et al. [14] is confirmed for the water contents above 5\%: the compressive strength decreases when the water content increases (Figure 5). However another interesting result is found: for low water content which are from the dry samples (in the atmospheric conditions) to $4 \%$, the mechanical characteristics do not vary, which corresponds to a constant suction in this range of water content (Figure 6).

\subsection{Explanations}

Gélard et al. [16] showed that the cohesion of low clayey soil material was primarily provided by the capillary force between particles. Halsey and Levine [17], Fisher and Israelachvili [18] showed that there was a range of water content in which the capillary force is constant (independent of the amount of water in the material). The attractive force due to capillary condensation bridge between two spherical particles with a rough surface has four regimes. In regime 1 (asperity regime), the condensation takes place between two asperities in contact and the cohesive force increases non-linearly with the amount of water. In 
regime 2 (roughness regime) the force increases linearly with the amount of water due to the lateral spreading of the liquid bridge over several asperities. However, in this regime, the meniscus is not yet sensitive to the average spherical curvature of the particles. In regime 3 (classical regime), the meniscus is no longer sensitive to the roughness and the cohesive force is independent to the amount of water, as between two smooth spheres. For the samples whose water content is between 2 and $4 \%$, its water contents fall in this third regime, which explains the constancy of the attractive force. When the water content increases, the samples are in regime 4 (saturation regime), neighboring liquid bridges merge, the cohesion decreases. Our samples which had a natural drying do not fall within regimes 1 or 2 because there was a balance with the atmospheric pressure.

\section{Conclusions and prospects}

The water sensitivity of the rammed-earth material and the earth material is a negative point in the public eye. This paper has shown, however, that there was a range of water content in which the mechanical characteristics of rammed-earth material were constant. With water content not exceeding $4 \%$, the material still retains its mechanical characteristics as at its dry state (in the atmospheric conditions). This explains what we often see on site: a slight increase in water content of rammed-earth walls (e.g. by rain) does not accompany a sudden drop in the wall's strength. Qualitative explanations at the microscopic level have been proposed to analyse the results.

Poisson ratio was determined for the first time to our knowledge. In this study, the Poisson ratio varied from about 0.2 for the "dry" samples (at ambient conditions) to 0.4 for the wet samples (just after manufacturing). This coefficient can be used in modeling structures, in static or dynamic.

The relationship between the suction and the compression strength in this study is similar to that in the study of Jaquin et al. [14]. This makes us think that this relationship is valid for several different soils. This remark will be verified in the future with other soil types.

The soil used in this study contains $5 \%$ clay which is the lower limit for unstabilised rammed-earth (Walker et al.). Studies on other clayey soils are needed to verify whether the results will be different to the results of this study.

The samples in this study were manufactured in laboratory. To link the results obtained in this study with those of in-situ walls, the correlation coefficients are necessary. Calibration curves will be required.

\section{Acknowledgements}

The authors wish to thank E. Hamard from the ENTPE for his assistance and $\mathrm{N}$. Meunier, an experienced rammed-earth mason, for his advice and help. Jenny is warmly thanked for her revision of the English of this paper. 


\section{References}

[1] Walker P, Keable R, Martin J, Maniatidis V. "Rammed earth-Design and construction guidelines", BRE Bookshop, 2005.

[2] Hall M, Djerbib Y. "Rammed earth sample production: context, recommendations and consistency", Construction and Building Materials, 18, pp. 281-286, 2004.

[3] Bui Q B, Morel J C, Reddy B V V, Ghayad W. "Durability of rammed earth walls exposed for 20 years to natural weathering", Building and Environment, vol. 44 (5), pp. 912-919, 2009.

[4] Hall M, Djerbib Y. "Moisture ingress in rammed earth: Part 1-the effect of soil particle-size distribution on the rate of capillary suction", Construction and Building Materials, 18, pp. 269-280, 2004.

[5] Taylor P, Fuller R J, Luther M B. "Energy use and thermal comfort in a rammed earth office building", Energy and Building, 40, pp. 793-800, 2008.

[6] Taylor P, Luther M B. "Evaluating rammed earth walls: a case study", Solar Energy, 76, pp. 79-84, 2004.

[7] Paul W L, Taylor P A. "A comparison of occupant comfort and satisfaction between a green building and a conventional building", Building and Environment, 43, pp. 1858-1870, 2008.

[8] Bui Q B, Morel J C, Hans S, Meunier N. "Compression behaviour of nonindustrial materials in civil engineering by three scale experiments: the case of rammed earth", Materials and Structures, vol. 42, № 8, pp. 11011116, 2009.

[9] Bui Q B, Morel J C. "Assessing the anisotropy of rammed earth", Construction and Building Materials, 23, pp. 3005-3011, 2009.

[10] Maniatidis V, Walker P. "Structural Capacity of Rammed Earth in Compression", Journal of Materials in Civil Engineering, Vol. 20, No. 3, pp. $230-238,2008$.

[11] Morel J C, Mesbah A, Oggero M and Walker P. "Building houses with local materials: means to drastically reduce the environmental impact of construction", Building and Environment, 36, pp. 1119-1126, 2001.

[12] Fodde E. "Traditional earthen building techniques in Central Asia", Int. $J$. of Architectural Heritage, 3, pp. 145-168, 2009.

[13] Olivier M, Mesbah A. "Constitutive equations for compacted soils", Proceedings of the first international conference on Unsaturated Soils, Paris, pp.765-773, 1995.

[14] Jaquin P A, Augarde C E, Gallipoli D, Toll D G. "The strength of unstabilised rammed earth materials", Géotechnique 59, No. 5, pp. 487490, 2009.

[15] Delage P, Cui Y-J. «L'eau dans les sols non saturés», Techniques de l'Ingénieur, C301, 2003.

[16] Gélard D et al. "When physics revisit earth construction: recent advances in the understanding of the cohesion mechanisms of earthen materials", Int. Symposium on Earthen Structures, Bangalore, India, pp. 294-302, 2007. 
576 Structural Repairs and Maintenance of Heritage Architecture XII

[17] Halsey T C, Levine A J. "How Sandcastles Fall", Phys. Rev. Lett. 80, pp. 3141-3144, 1998.

[18] Fisher L R, Israelachvili J N. "Direct measurement of the effect of meniscus forces on adhesion: a study of the applicability of macroscopic thermodynamics to microscopic liquid interfaces", Colloids and Surfaces, 3, pp. 303-319, 1981. 